\title{
High heat conductivity of porous ceramics as oil carrier for novel designed smoke atomizer
}

\author{
Tengfei DENG ${ }^{1, \dagger}$, Junjie HONG ${ }^{1}$, Bing LIU' ${ }^{2}$, Huachen LIU² and Yikun CHEN ${ }^{2}$ \\ ${ }^{1}$ State Key Laboratory of Silicate Materials for Architectures, Wuhan University of Technology, Wuhan Hubei 430070, China \\ ${ }^{2}$ China Tobacco Hubei Industrial Limited Liability Company, Wuhan Hubei 430040, China
}

\begin{abstract}
Porous ceramic of high heat conductivity was prepared by using $\mathrm{SiC}$ and $\mathrm{Al}(\mathrm{OH})_{3}$ as main raw materials and was applied as oil carrier of smoke atomizer. Graphite and starch were added as pore-forming agents. Results exhibited that the mixture of two pore-forming agents has significant effect on apparent porosity and bending strength of the samples. The mixture of pore formers starch and graphite kept the porosity and remained the sample strength. The best comprehensive physical property was obtained by the additional pore-forming agent that was composed by starch of $40 \mathrm{wt} \%$ and graphite of $25 \mathrm{wt} \%$. The oil absorption rate and bending strength met the requirements of porous ceramic as oil absorber. The phase compositions are $\mathrm{SiC}, \mathrm{SiO}_{2}$ and needle-like mullite after fired at $1325^{\circ} \mathrm{C}$. The distribution of pores was uniform. Smoke atomizer was designed through the combination of porous ceramic and metal ceramic heater (MCH) disk. A simulation of heat conductivity involved in the smoke atomizer was carried out. Both computational simulation and experiment were taken to figure out the efficiency of gas generation by different porous ceramics.

@2018 The Ceramic Society of Japan. All rights reserved.
\end{abstract}

Key-words : SiC, Porous ceramics, Oil absorption, Thermal conductivity, Temperature field

[Received March 30, 2018; Accepted June 8, 2018]

\section{Introduction}

Cigarette has been considered as a popular hobby staple in the world for more than hundred years, and the sales are booming year by year. However, tobacco smoke contains some nasties linked with cancer which have prompted the governments to ban smoking in public. Thus, a completely new type of cigarette has been developed by many countries, which is called "Non combustion cigarette". As one of the typical products, "e-cigarette" (electronic cigarettes) has been gained an appreciation by many costumers. The "e-cigarette" recaptures the flavors of traditional tobac$\cos ^{1)}$ At the same time, a ninety five percent reduction ${ }^{2)}$ in toxic substances as nicotine and tar can be archived. On the other hand, quite apart from that, people around smoker can avoid suffering from tobacco smoke, ${ }^{3)}$ compared to traditional cigarette.

The lynchpin of "e-cigarette" is smoke atomizer. The structure of the first generation of atomizer is to twist the thin nickel-chromium wire carefully around the wick which is employed as absorber of tobacco oil. ${ }^{4)}$ The heating wire heats the oil in the wick and makes it to be atomized. The most common substances of the wick are flax, cotton or glass fiber. Re-heating flax or cotton wick always generates the burnt smell after placement of e-cigarette for a certain time and the glass fiber wick would have some

Corresponding author: T. Deng; E-mail: tengfei@kth.se fibers peeling off after it has been used repeatedly, which is very harmful to human health. As the most common industrial ceramic, porous ceramic is composed of inorganic nonmetallic materials which are reliable, nontoxic, cheap and stable. ${ }^{5)}$ Thus, this material is appropriate to be applied as oil absorber.

Clay and minerals are often used as raw materials to prepare this porous ceramics and the nickel-chromium alloy wire is still introduced as heating element. The drawback of clay or mineral based porous ceramics is its low thermal conductivity. Low thermal conductivity results in a low heating rate in porous ceramic and the whole atomization process becomes slow, so this presents a problem for many "e-cigarette" consumers.

A way of speeding up the atomization rate is to enhance heating power. But high heating power results in the temperature of heating wire sharply raise and the consequence is that more formaldehyde generates thereby. In addition, the thin heating wire causes asymmetric temperature distribution in the porous ceramic and carbonization of tobacco oil happens. Thus, a porous ceramic with higher thermal conductivity and a new heating mode are required to solve the problems which are mentioned above.

The main objective of the present work is to invent a new smoke atomizer. The smoke atomizer contains two parts: a) oil absorber with high thermal conductivity; b) stable and controllable heating element. The material silicon carbide ( $\mathrm{SiC}$ ) has many advantages, some of which 
are non-toxicity, high thermal conductivity and excellent thermal shock resistance. ${ }^{6)-9)}$ Those three attractive traits make $\mathrm{SiC}$ as the prime candidate for porous ceramic in smoke atomizer. Instead of nickel-chromium alloy wire, metal ceramic heater $(\mathrm{MCH})$, which is stable and with high heat efficiency, ${ }^{10)}$ is applied as the heater to heat the $\mathrm{SiC}$ porous ceramic. The study focuses on the preparation of porous $\mathrm{SiC}$ ceramics with high strength and high oil absorption rate. A simulation of heat conductivity involved in the whole smoke atomizer is carried out and the simulation results are proved in kind.

\section{Experiment}

\subsection{Material preparation}

Based on the studies by different researchers, ${ }^{11-14)}$ the main factors affecting the oil absorption were porosity and pore size. Therefore, this study intended to control the particle size of the pore-forming agent in order to control the porosity and pore size of porous ceramics. Starting materials were $\alpha$-SiC (Dan Jiangkou Hubei Silicon Carbide Co., Ltd.), $\mathrm{Al}(\mathrm{OH})_{3}$ ( $\mathrm{Zi}$ Bo Shangdong Industrial aluminum hydroxide Co., Ltd.), graphite (Hua Tai Qingdao graphite Co., Ltd.) and starch (Nai Hai Foshan starch Co., Ltd.). The chemical compositions and average particle sizes of the starting materials are listed in Tables 1 and 2, respectively. The purpose of this study is to make the porous ceramic with high thermal conductivity, so the major component in the sample was SiC. Small amount of $\mathrm{Al}(\mathrm{OH})_{3}$ was added to react with $\mathrm{SiO}_{2}$ and formed as mullite phase to enhance the bending strength. Graphite and starch are used together as an additional pore-forming agent. As a high-temperature pore-forming agent, graphite with lamellar structure can release gas at high temperature, preventing the filling of pores by the low melting component in the ceramic at high temperature. At lowtemperature, the exothermic reaction of starch will cause the large thermal expansion during the process at such temperature, which can ensure the stability and uniformity of pore structure and that is also very important for the improvement of porosity. The simultaneous use of the two pore-forming agents broadens the temperature range of releasing gas, increasing the porosity of the porous ceramic, and ensuring the body intact without cracking.

The mass ratio of $\mathrm{SiC}$ to $\mathrm{Al}(\mathrm{OH})_{3}$ was determined as $9: 1$. Based on the research, ${ }^{15)}$ the addition of graphite content was fixed as $25 \mathrm{wt} \%$. Another pore former was introduced to gain the best comprehensive properties of porous ceramic. The additional content of another pore former was fixed as $40 \mathrm{wt} \%$ after experimentally evaluation. The detail evaluation was given in supplementary material. To gain an insight of the effect of different pore forming agent on the oil absorption rate, different combination of pore formers is presented in Table 3. The detail discussion of the batch formula in Table 3 was presented in the next section.

The starting materials were ball-milled for $30 \mathrm{~min}$, and mixed uniformly. The polyvinyl alcohol (PVA) with a concentration of $5 \mathrm{wt} \%$ was added to the mixed powders for granulation. Green bodies with diameter of $7 \mathrm{~mm}$ and thickness of $2 \mathrm{~mm}$ were prepared under a pressure of $5 \mathrm{kN}$, which were prepared as oil absorber carrier of the smoke atomizer. The rectangular bar with size of $37 \mathrm{~mm} \times$ $6 \mathrm{~mm} \times 5 \mathrm{~mm}$ were prepared under a pressure of $30 \mathrm{kN}$, which were employed to test the physical properties. The samples were dried at $100^{\circ} \mathrm{C}$ for $24 \mathrm{~h}$ to remove the moisture. In order to figure out the best comprehensive performance of the samples, the pressure-less firing of compact sample A6 was conducted from 1300 to $1400^{\circ} \mathrm{C}$ with an interval of $25^{\circ} \mathrm{C}$ with heating rate of $4^{\circ} \mathrm{C} / \mathrm{min}$. $1325^{\circ} \mathrm{C}$ was used as the firing temperature after comparison of the firing properties.

In order to meet the actual requirements of the oil absorber, the prepared porous ceramic and $\mathrm{MCH}$ disk were stuck together by inorganic binder to form as the atomizer. $\mathrm{MCH}$ disk used in this study is a commercial product, so very brief introduction of production is presented in this article. $96 \mathrm{wt} \% \mathrm{Al}_{2} \mathrm{O}_{3}$ ceramic was used as carrier. Tungsten was the heating element and screen printed on one side of the green body (the green body after sintering is $96 \mathrm{wt} \% \mathrm{Al}_{2} \mathrm{O}_{3}$ ceramic). After screen printing, the green

Table 1. Chemical compositions of starting materials/wt \%

\begin{tabular}{lcrrrrrrrrrr}
\hline starting materials & $\mathrm{SiC}$ & $\mathrm{SiO}_{2}$ & $\mathrm{Al}_{2} \mathrm{O}_{3}$ & $\mathrm{Fe}_{2} \mathrm{O}_{3}$ & $\mathrm{CaO}$ & $\mathrm{SO}_{3}$ & $\mathrm{MgO}^{2}$ & $\mathrm{~K}_{2} \mathrm{O}$ & $\mathrm{Na}_{2} \mathrm{O}$ & $\mathrm{I} . \mathrm{L}$ & $\mathrm{Total}^{2}$ \\
\hline Silicon Carbide & 99.52 & - & 0.17 & 0.19 & 0.09 & 0.03 & - & - & - & - & 100 \\
Industrial aluminum hydroxide & - & 1.57 & 56.52 & 0.12 & 5.21 & 0.03 & 0.37 & 0.09 & 0.12 & 35.97 & 100 \\
Graphite & - & 8.57 & 2.12 & 4.36 & 2.94 & 0.13 & 0.67 & 0.17 & 0.09 & 80.95 & 100 \\
Residual ash after graphite burning & - & 44.99 & 11.13 & 22.89 & 15.43 & - & - & 0.89 & 0.47 & - & 100 \\
\hline
\end{tabular}

Table 2. Average particle sizes of starting materials $(\mu \mathrm{m})$

\begin{tabular}{lc}
\hline Starting materials & Average particle sizes \\
\hline Silicon Carbide & 63 \\
Industrial Aluminum hydroxide & 91.201 \\
Starch(1\#) & 15.136 \\
Starch(2\#) & 168.07 \\
Graphite(1\#) & 34.674 \\
Graphite(2\#) & 171.75 \\
\hline
\end{tabular}

Note: the same starch with two particle sizes and the same graphite with two particle sizes.
Table 3. Batch formulae of different samples (wt \%)

\begin{tabular}{ccccccc}
\hline \multirow{2}{*}{$\begin{array}{c}\text { Sample } \\
\text { No. }\end{array}$} & $\mathrm{SiC}$ & $\mathrm{Al}(\mathrm{OH})_{3}$ & \multicolumn{4}{c}{ Pore-forming agent(In addition) } \\
\cline { 4 - 7 } & & & $\begin{array}{c}\text { Starch } \\
(1 \#)\end{array}$ & $\begin{array}{c}\text { Starch } \\
(2 \#)\end{array}$ & $\begin{array}{c}\text { Graphite } \\
(1 \#)\end{array}$ & $\begin{array}{c}\text { Graphite } \\
(2 \#)\end{array}$ \\
\hline $\mathrm{A} 1$ & 90 & 10 & 40 & 0 & 25 & 0 \\
$\mathrm{~A} 2$ & 90 & 10 & 40 & 25 & 0 & 0 \\
$\mathrm{~A} 3$ & 90 & 10 & 40 & 0 & 0 & 25 \\
$\mathrm{~A} 4$ & 90 & 10 & 0 & 0 & 40 & 25 \\
$\mathrm{~A} 5$ & 90 & 10 & 0 & 40 & 25 & 0 \\
$\mathrm{~A} 6$ & 90 & 10 & 0 & 40 & 0 & 25 \\
\hline
\end{tabular}


body along with heating element was hot pressed with another green body. After that, the whole body was sintered at $1600^{\circ} \mathrm{C}$ under the $\mathrm{H}_{2}$ atmosphere.

The temperature field of the whole smoker atomizer during heating process was simulated by ANSYS15.0 software. The thermal conductivity property of the composite ceramics was evaluated by comparing the results of the simulated calculation with the actual test.

\subsection{Characterization}

The chemical compositions of all the raw materials were determined by X-ray fluorescence (XRF) analyzer (AxiosAdvanced, PANalytical B.V., Netherlands). A thermogravimetric analysis (TG) and differential thermal analysis (DTA) of different mixtures were performed from ambient temperatures to $1500^{\circ} \mathrm{C}$ with a heating rate of $10^{\circ} \mathrm{C} / \mathrm{min}$ by using a TG/DTA simultaneous thermal analyzer (Netzsch STA2500, German). Apparent porosity $(\mathrm{Pa} / \%)$, water absorption $(\mathrm{Wa} / \%)$ and bulk density $\left(\rho / \mathrm{g} \cdot \mathrm{cm}^{-3}\right)$ were measured by AUY120 electronic analytical balance (Japanese Shimazu) through static weighing method. The bending strength was measured by Computer Control Electronic Universal Test Machine (Shenzhen Reger Instrument Co., Ltd., China). X-ray diffraction (XRD) patterns were obtained by using a D/MAX-IIIA diffractometer (Rigaku Corporation, Japan) equipped with a copper target, scintillation detector and graphite monochromator with $\mathrm{Cu} \mathrm{K} \alpha$ ( $\lambda=1.54 \AA)$ radiation. Scanning electron microscope (SEM) (JEOL JSM-5615LV, JEOL Ltd., Japan) was employed to investigate the microstructure of samples. The element analysis of the fractured surface of the samples were investigated by the energy dispersive spectroscopy (EDS) with a vacuum of $9.7 \times 10^{-5} \mathrm{~Pa}$ and an accelerate voltage of $15 \mathrm{kV}$. The heat capacity and the thermal conductivity were measured by $\mathrm{TC}-7000 \mathrm{H}$ laser flash thermal constant analyzer (ULVAC SINKU-RIKO. Inc., Japan).
The temperature field of porous ceramic was simulated by ANSYS 15.0.

The oil absorption $\left(O_{\mathrm{a}} / \%\right)$ of samples were measured by capillary action method.

$O_{\text {a }}$ was calculated according to Eq. (1)

$$
O_{\mathrm{a}}=\frac{M_{1}-M_{0}}{M_{0}} \times 100 \%
$$

where $M_{0}$ is the dry weight and $M_{1}$ is the quality after oil absorption.

\section{Results and discussion}

\subsection{TG-DTA analysis}

The addition of starch is evaluated first. The heating process is determined according to the TG-DTA analysis. Figure 1 shows the TG-DTA results of the mixture of sample A1. The mass loss before $100^{\circ} \mathrm{C}$ is caused by removing of the free water. The endothermic peak at $278^{\circ} \mathrm{C}$ corresponds to the thermal decomposition of industrial aluminum hydroxide, ${ }^{16)}$ which would take off the hydroxyl and release gas. Consequently, the sample should be soaked at $278^{\circ} \mathrm{C}$ and the heating rate should be slowed down near this temperature point. Starch burns with severe weightlessness at $300.5^{\circ} \mathrm{C}$. The exothermic peak is $324.2^{\circ} \mathrm{C}$, which is related to the thermal decomposition of starch, ${ }^{17)}$ and the oxidation process completes before $500^{\circ} \mathrm{C}$. Therefore, it must be slowly heated in this temperature range to facilitate the exclusion of starch. The oxidation of graphite begins at $600^{\circ} \mathrm{C}$ and it completes at $900^{\circ} \mathrm{C}$. The exothermic peak at $767.9^{\circ} \mathrm{C}$ corresponds to the oxidation of graphite. ${ }^{18)}$ According to the relevant literature, ${ }^{19}$ ) oxidation of $\mathrm{SiC}$ occurs at temperatures above $750^{\circ} \mathrm{C}$. With temperature arising, the oxidation of more $\mathrm{SiC}$ leads to the weight gain continually. With the temperature increasing, liquid phase generates and the generation of liquid phase enhances the bonding strength of $\mathrm{SiC}$ particles. Meanwhile, the $\mathrm{SiO}_{2}$

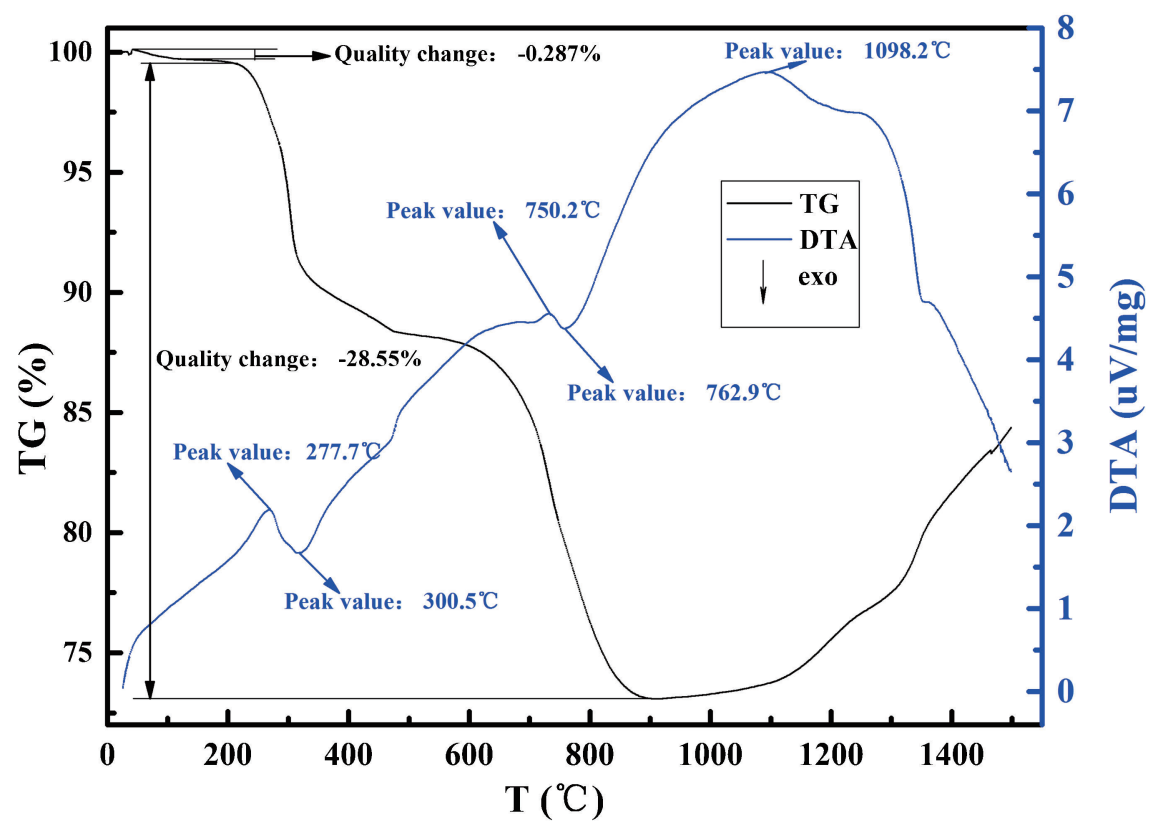

Fig. 1. TG-DTA results of the mixture of sample A1. 
would react with $\mathrm{Al}_{2} \mathrm{O}_{3}$ to form mullite. The endothermic peak at $1098.2^{\circ} \mathrm{C}$ corresponds to the formation of mullite reacted by $\mathrm{SiO}_{2}$ and $\mathrm{Al}_{2} \mathrm{O}_{3} .{ }^{20}$ )

\subsection{Effect of pore-forming agent on physical properties of samples}

The physical properties of the samples are listed in Table 4. The oil absorption rates of all kinds of samples are shown in Fig. 2. Sample A6 is with the highest oil absorption rate but weak oil absorption capacity of sample A4 is observed. The batch formula of samples A2 and A4 are desired to compare the effect of a single kind of pore

Table 4. Testing results of open porosity and bending strength of series A

\begin{tabular}{ccc}
\hline Sample No. & Open porosity $(\%)$ & Bending strength (MPa) \\
\hline A1 & 51.58 & 14.03 \\
A2 & 52.79 & 13.29 \\
A3 & 52.89 & 13.56 \\
A4 & 31.22 & 38.46 \\
A5 & 53.11 & 13.22 \\
A6 & 53.64 & 12.94 \\
\hline
\end{tabular}

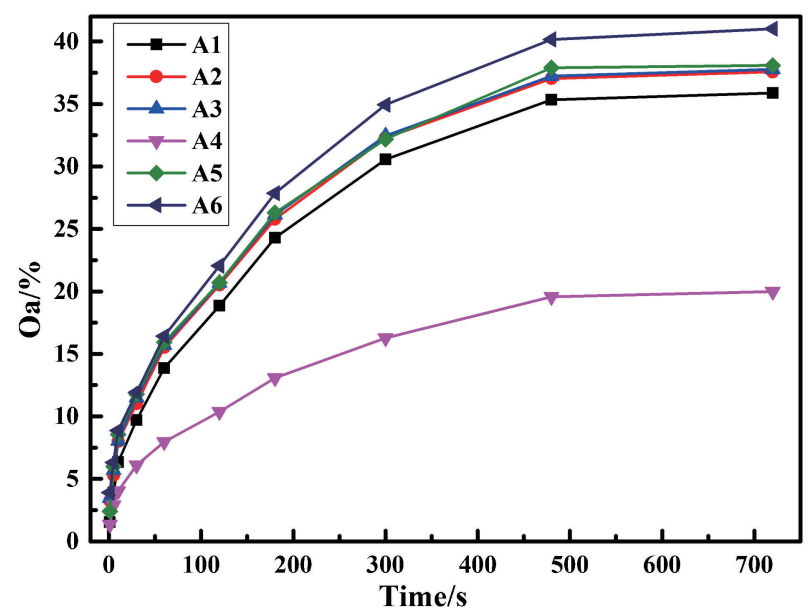

Fig. 2. Oil absorption rates of all kinds of samples. former and a combination of two different pore formers on the physical properties of samples. Sample A2 has only starch as pore former. Ocular examinations show that the $80 \%$ products of sample A2 after experiments are inferiors, which are with many visible severe cracks. Those inferiors are with very low bending strength. On the other hand, the rest products of sample A2 without visible cracks are used to do the measurements of physical properties. The cracking is strongly related to the burning of starch. As shown in Fig. 1, the thermal decomposition of starch begins at $300^{\circ} \mathrm{C}$ and completes at $500^{\circ} \mathrm{C}$. Therefore, in this temperature range, the burning of starch results in a large amount of gas releasing from the sample, and thus easily makes the body cracking. On the other hand, as listed in Table 4, the apparent porosity of sample A4 slumps and its bending strength significantly arises. Formulation of sample A4 has only graphite as the pore former. The oxidation of graphite begins at $600^{\circ} \mathrm{C}$, and completes at $900^{\circ} \mathrm{C}$. However, it should be noticed that as a high temperature pore former, graphite always has more ash residue after burning. ${ }^{21)}$ The oxidation of $\mathrm{SiC}$ particles and the impurities in the raw materials generate siliceous liquid phase at high temperature. Siliceous liquid phase is always with high melting point and high viscosity value. ${ }^{22)}$ As shown in Table 1, the residual ash contains $22.89 \mathrm{wt} \%$ of $\mathrm{Fe}_{2} \mathrm{O}_{3}$ and $15.43 \mathrm{wt} \%$ of $\mathrm{CaO}$. The lowest eutectic point of $\mathrm{SiO}_{2}-\mathrm{CaO}-\mathrm{Fe}_{2} \mathrm{O}_{3}-\mathrm{Al}_{2} \mathrm{O}_{3}$ is lower than $1200^{\circ} \mathrm{C},{ }^{22)}$ so the high content of $\mathrm{CaO}$ and $\mathrm{Fe}_{2} \mathrm{O}_{3}$ results in a low melting point of liquid phase. It is also suggested that the amount of liquid phase increases by the presence of those two chemicals. The SEM micrograph of sample A4 (without etching) after fired at $1325^{\circ} \mathrm{C}$ is presented in Fig. 3. The chemical composition of surface area by EDS analysis is listed in Table 5. The results evidentially show that the liquid phase covers the surface of the sample. On the other hand, $\mathrm{CaO}$ and $\mathrm{Fe}_{2} \mathrm{O}_{3}$ also lower the viscosity value of the liquid phase and make the liquid phase flow easier. Thus, the fully use of graphite as the pore former clogs up the connected pores. The reduction of number of pores in the sample has brought down the open porosity and oil

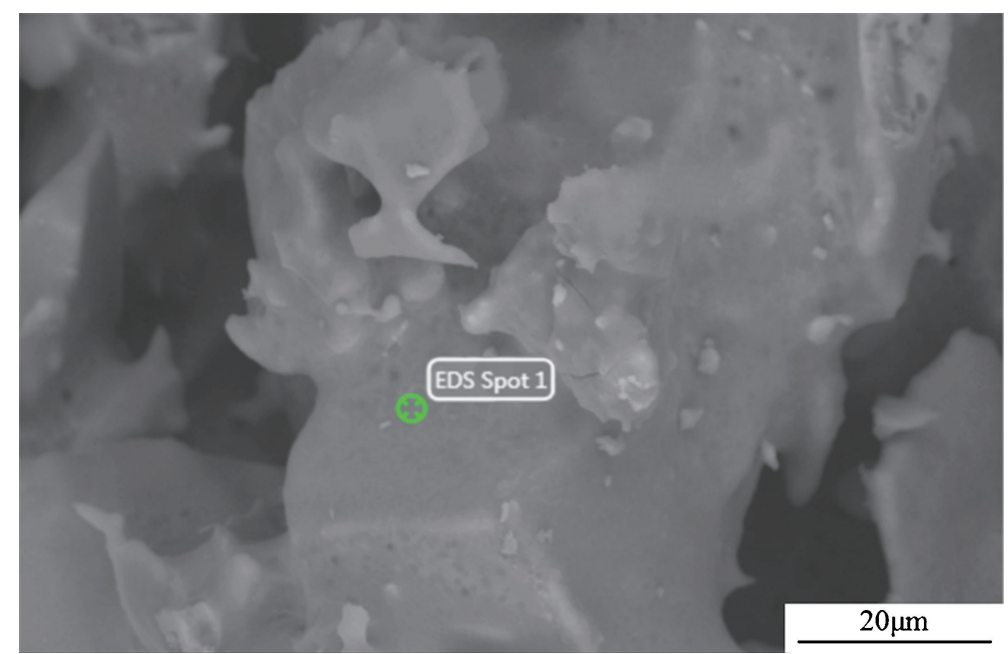

Fig. 3. SEM micrograph of sample A4 (without etching) after fired at $1325^{\circ} \mathrm{C}$. 
Table 5. Chemical compositions of residual ash and liquid phase

\begin{tabular}{ccccccccccc}
\hline $\begin{array}{c}\text { Chemical } \\
\text { composition }\end{array}$ & $\mathrm{SiO}_{2}$ & $\mathrm{Al}_{2} \mathrm{O}_{3}$ & $\mathrm{Fe}_{2} \mathrm{O}_{3}$ & $\mathrm{CaO}$ & $\mathrm{SO}_{3}$ & $\mathrm{MgO}$ & $\mathrm{K}_{2} \mathrm{O}$ & $\mathrm{Na}_{2} \mathrm{O}$ & Total \\
\hline Spot 1 & 41.12 & 6.56 & 36.25 & 13.90 & - & - & 1.55 & 0.62 & 100 \\
\hline
\end{tabular}
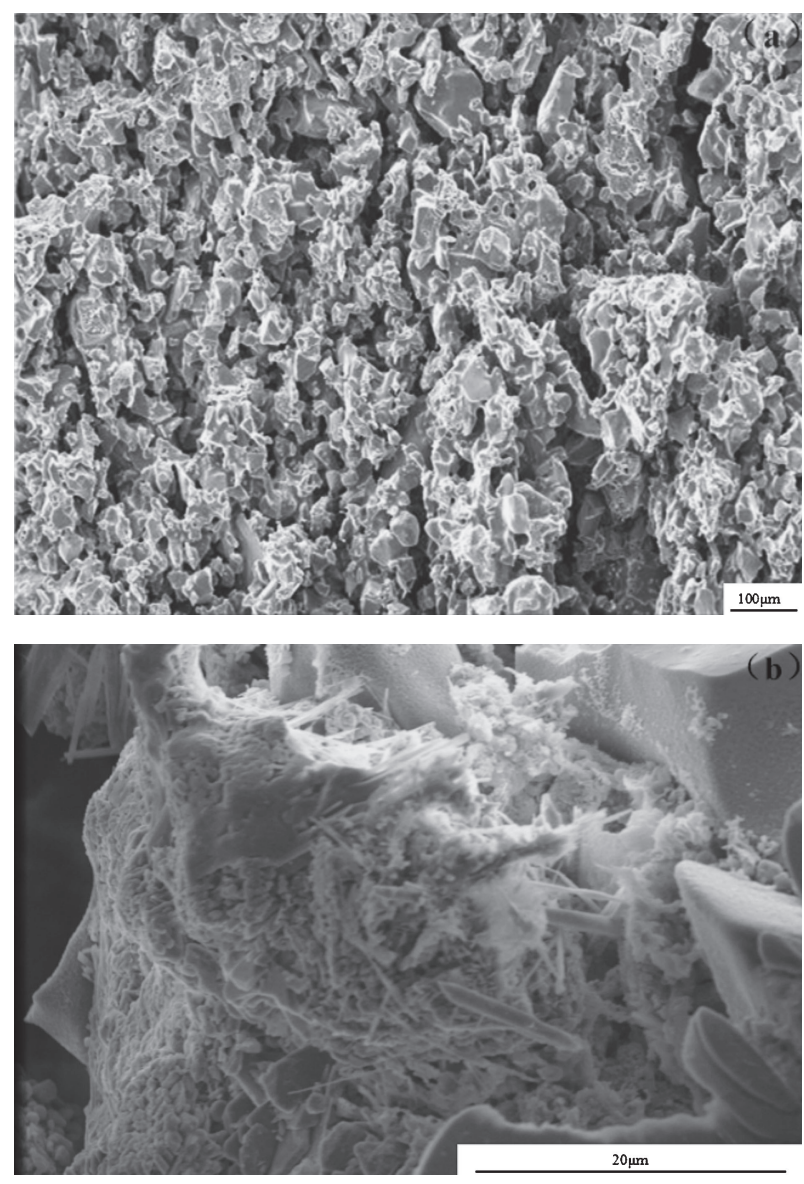

Fig. 4. The cross-sectional morphology of sample A6 after fired at $1325^{\circ} \mathrm{C}$ (a) without etching (b) etched by $5 \% \mathrm{HF}$ solution for $60 \mathrm{~s}$.

absorption rate but enhances the bending strength of the sample consequently. It is noticeable that compared with graphite, the starch has very little residual ash. The purity of starch ensures the formation of pores at low temperature. The remaining of pores in the sample at high temperature depends on the burning of graphite. Therefore, using a mix of pore formers starch and graphite is necessary to remain the porosity and sample strength.

\subsection{Phase composition and microstructure of samples}

To figure out the pores shape and distribution in the sample after experiment, secondary electron image with low magnification is employed. Figure 4(a) is the crosssectional morphology of sample A6 after fired at $1325^{\circ} \mathrm{C}$ without etching. A large number of connected pores with irregular shapes distribute in the sample uniformly. The mean size of the pores is roughly tallied as $21.1 \mu \mathrm{m}$. The

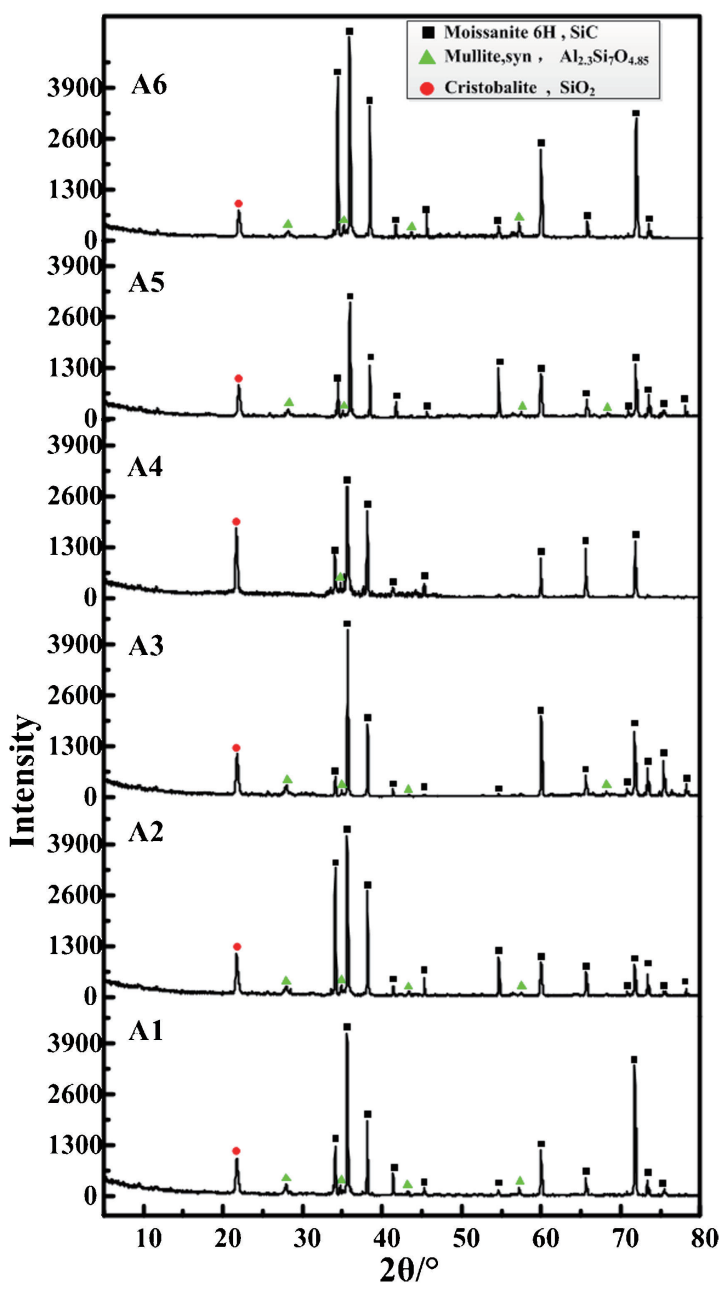

Fig. 5. XRD of all samples after fired at $1325^{\circ} \mathrm{C}$.

SEM microphotograph with high magnification is introduced to gain an insight into the microstructure of the sample. Figure 4(b) presents the cross-sectional morphology of sample A6 after fired at $1325^{\circ} \mathrm{C}$ and etched by $5 \%$ $\mathrm{HF}$ solution for $60 \mathrm{~s}$. The needle-like crystals were clearly observed. As shown in Fig. 5, XRD patterns reveal that only two phases, namely cristobalite and mullite, are found in all samples after fired at $1325^{\circ} \mathrm{C}$. The crisobalite is generated according to the oxidation of $\mathrm{SiC}$. Mullite phases are formed by the reaction of $\mathrm{SiO}_{2}$ with $\mathrm{Al}_{2} \mathrm{O}_{3}$. ${ }^{23), 24)}$

$$
3 \mathrm{Al}_{2} \mathrm{O}_{3}+2 \mathrm{SiO}_{2}=3 \mathrm{Al}_{2} \mathrm{O}_{3} \cdot 2 \mathrm{SiO}_{2}
$$

The mullite in the sample is synthesized by an in-situ reaction. During the firing process, a large amount of gas will be released inside the sample. The gas transportation will promote the growth of the mullite nuclei along the $c$ axis, causing the mullite nuclei grow axially into whiskers. Glass with lower melting point is included around neck area among grains, which can greatly enhance the strength. Meanwhile, the shape of formed mullite is needle, which can play the role of "fiber toughness"23) in the sample and enhance mechanical properties. The presences of mullite phases and glassy phase greatly improve the mechanical properties of porous $\mathrm{SiC}$ ceramics. 


\subsection{Simulation of heat conduction}

The heat conduction in the porous ceramics is essentially important for the atomization of the tobacco oil. Different raw materials result in different thermal conductivities of porous ceramics. However, the chamber of the "e-cigarette" is very small, so whether different conductivities of different porous ceramics have huge difference on the efficiency of gas generation should be proved by both computational simulation and experimental research.

The simulation of heat conductivity in the porous ceramics has been studied recently, ${ }^{25}$ ) so this study main focuses on the temperature distribution in the combination of porous ceramic and $\mathrm{MCH}$. The temperature distribution and heat flux in the smoker atomizer are calculated through the commercial software ANSYS 15.0. The smoke atomizer is schematically illustrated in Fig. 6. The whole device contains two domains. The heating device at the bottom of smoke atomizer is metal ceramics heater $(\mathrm{MCH})$, whose diameter is of $6 \mathrm{~mm}$ and thickness is of $0.4 \mathrm{~mm}$. A very thin $\mathrm{MCH}$ disk is required here to reduce the heat absorption by ceramic carrier of $\mathrm{MCH}$ disk. The porous ceramic is used as oil absorber and attached on the surface of $\mathrm{MCH}$. The porous ceramics is $7 \mathrm{~mm}$ in diameter and $2 \mathrm{~mm}$ in thickness. The simulation in this study makes the following assumptions: 1) The role of microscopic defects is not considered. 2) The porous ceramics and $\mathrm{MCH}$ disk are directly contacted under the gravity, and all material properties are perfectly elastic during heat transfer. 3) The thermal parameters of the porous ceramics are set as fixed values. Finite element method is used to calculate the temperature field. The main parameters of the material are density, thermal diffusivity, specific heat capacity and thermal conductivity. The thermal conductivities of different porous ceramics are tested to make the simulation more reliable. Sample A6 is prepared in this

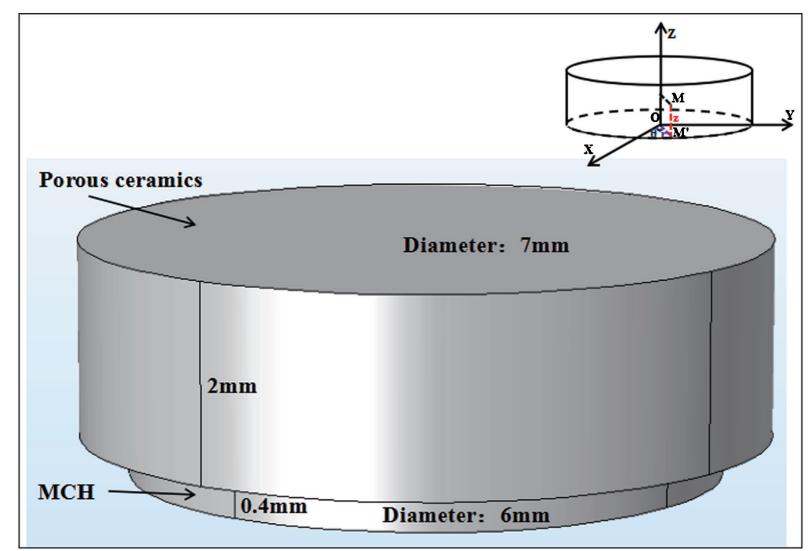

Fig. 6. Schematic illustration of smoke atomizer. study and the other porous ceramics are supplied by a commercial supplier. The porous ceramics are composited with different raw materials. As shown in Fig. 7, a little change of thermal conductivities of different samples is found with temperature arising. Therefore, in this simulation, the average values of these thermodynamic parameters are taken at the temperature in the range of 100 $300^{\circ} \mathrm{C}$. The physical parameters used in this simulation are shown in Table 6.

For isotropic three-dimensional models, the governing equations of heat conduction in solids are analyzed. In the cylindrical coordinate system, the equation used in the calculation is expressed as follow: ${ }^{26)}$

$$
\begin{aligned}
& \frac{1}{r} \frac{\partial}{\partial r}\left(r \lambda \frac{\partial T}{\partial r}\right)+\frac{1}{r^{2}} \frac{\partial}{\partial \theta}\left(\lambda \frac{\partial T}{\partial \theta}\right)+\frac{\partial}{\partial z}\left(\lambda \frac{\partial T}{\partial z}\right)+Q \\
& \quad=\rho C_{\mathrm{P}} \frac{\partial T}{\partial t}
\end{aligned}
$$

Where $r$ is the distance between the origin $\mathrm{O}$ and the projection $\mathrm{M}^{\prime}$ of the arbitrary point $\mathrm{M}, \theta$ the angle, $z$ the vertical distance between origin $\mathrm{O}$ and point $\mathrm{M}, Q$ the heat generated.

In order to solve the above partial differential equations of heat conduction, the initial conditions and boundary conditions of a particular problem are needed. The $\mathrm{MCH}$ disk is heated up from 20 to $300^{\circ} \mathrm{C}$ in $1 \mathrm{~s}$ and then the temperature of the disk is stabilized at $300^{\circ} \mathrm{C}$. The above assumption is given according to the real experiment. The temperature of oil gasification is around $200^{\circ} \mathrm{C}$, and this simulation sets the heating temperature at $300^{\circ} \mathrm{C}$ for the porous ceramics. The boundary condition is that there is no outflow of heat.

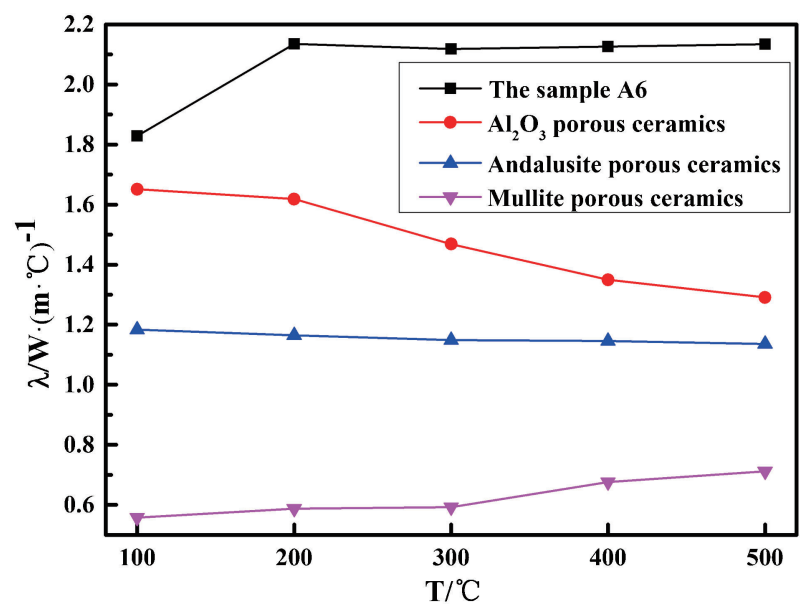

Fig. 7. Thermal conductivities of different samples as function of temperature.

Table 6. The physical parameters used in numerical simulation

\begin{tabular}{cccccc}
\hline Location & Major material & $\rho\left(\mathrm{kg} / \mathrm{m}^{3}\right)$ & $\alpha\left(\mathrm{m}^{2} / \mathrm{s}\right)$ & \multicolumn{1}{c}{$C_{\mathrm{p}}\left[\mathrm{J} /\left(\mathrm{kg} \cdot{ }^{\circ} \mathrm{C}\right)\right]$} & $\lambda\left[\mathrm{W} /\left(\mathrm{m} \cdot{ }^{\circ} \mathrm{C}\right)\right]$ \\
\hline Smoke atomizer 1 & $\mathrm{SiC}$ & $1.355 \times 10^{3}$ & $2.527 \times 10^{-6}$ & $0.759 \times 10^{3}$ & 2.599 \\
Smoke atomizer 2 & $\mathrm{Al}_{2} \mathrm{O}_{3}$ & $2.129 \times 10^{3}$ & $1.344 \times 10^{-6}$ & $0.577 \times 10^{3}$ & 1.651 \\
Smoke atomizer 3 & Andalusite & $1.541 \times 10^{3}$ & $0.741 \times 10^{-6}$ & $1.021 \times 10^{3}$ & 1.156 \\
Smoke atomizer 4 & Mullite & $1.674 \times 10^{3}$ & $0.59 \times 10^{-6}$ & $0.595 \times 10^{3}$ & 0.587 \\
\hline
\end{tabular}




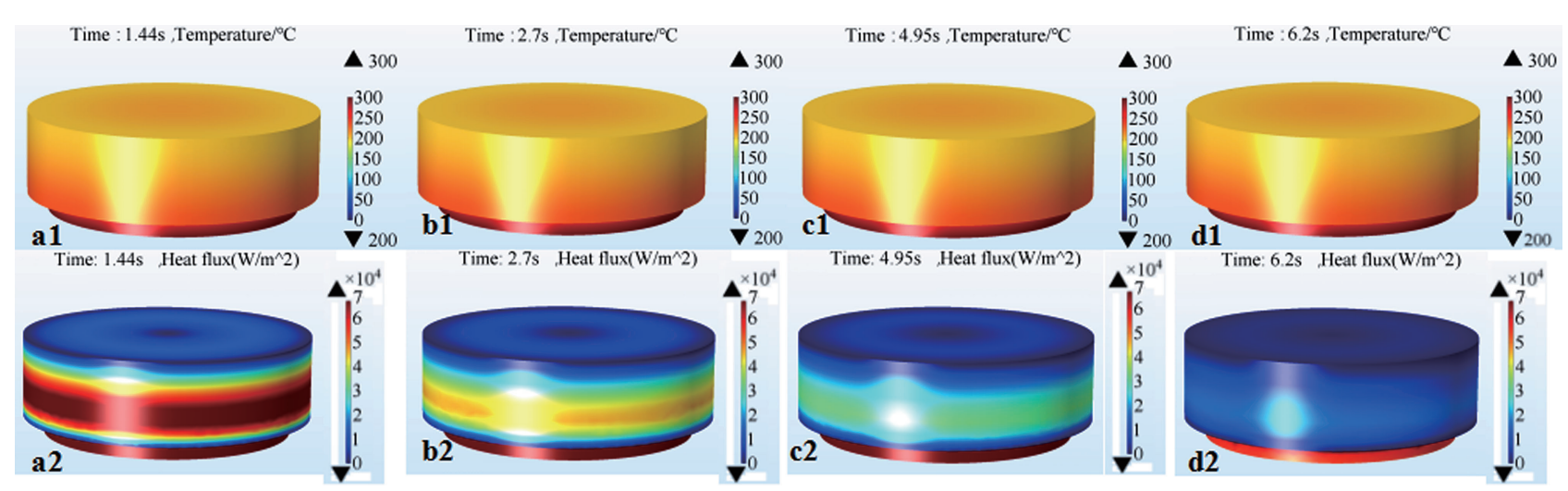

Fig. 8. Time needed for the surface temperature of different porous ceramics heating up from ambient temperature to $200^{\circ} \mathrm{C}$ (a1-d1) and the heat flux of different samples (a2-d2) (a) smoke atomizer 1 (b) smoke atomizer 2 (c) smoke atomizer 3 (d) smoke atomizer 4.
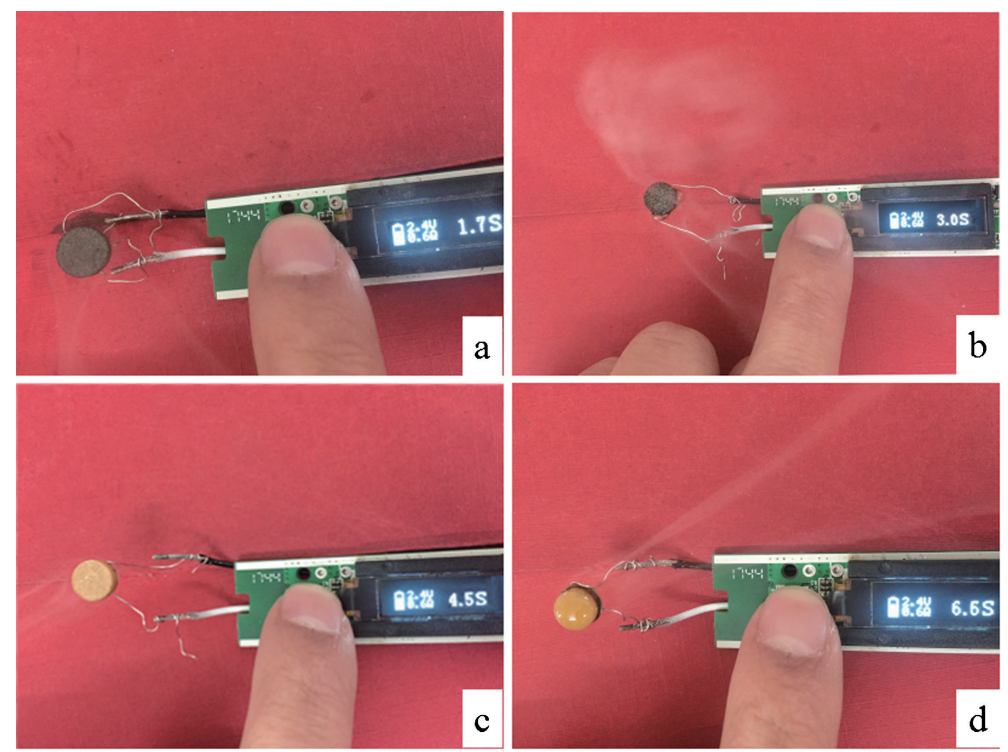

Fig. 9. Real experiment of time needed for gas generation from the smoke atomizer 1 to 4 (a) smoke atomizer 1

(b) smoke atomizer 2 (c) smoke atomizer 3 (d) smoke atomizer 4.

Heat flux is introduced to reflect the heating rate of porous ceramics in this paper. According to Fourier's law: ${ }^{27)}$

$$
J_{\mathrm{T}}=-\lambda \frac{\mathrm{d} T}{\mathrm{~d} r}
$$

Where in the unit area perpendicular to the direction of the transmission, $J_{\mathrm{T}}\left(\mathrm{W} \cdot \mathrm{m}^{-2}\right)$ is the heat transfer rate in the radius $r(\mathrm{~m})$ direction

The atomization temperature of tobacco oil is around $200^{\circ} \mathrm{C}$. As the simulation studies the heat transfer in the porous ceramic without oil inside, the temperature of the porous ceramic must be higher than $200^{\circ} \mathrm{C}$ to satisfy the requirement of gas generation. The heat is transferred from $\mathrm{MCH}$ disk to the surface of the porous ceramic. The temperature in most part of the porous ceramics must be higher than $200^{\circ} \mathrm{C}$, if the surface temperature is $200^{\circ} \mathrm{C}$. The oil should be atomized at this stage consequently. Figure 8 presents the time needed for the surface temperature of different porous ceramics heating up from ambient temperature to $200^{\circ} \mathrm{C}$. The calculated results of heat flux in the porous ceramic are also given in Fig. 8. The device in Fig. 8(a) is sample A6 prepared in this study and combined with MCH disk. As an oil absorber, Sample A6 is with the highest thermal conductivity among the four porous ceramics. The calculation shows that only $1.44 \mathrm{~s}$ are required for the surface temperature arising to $200^{\circ} \mathrm{C}$. However, the device in Fig. 8(d) is the mullite porous ceramic attached on the MCH disk. $6.2 \mathrm{~s}$ are needed for the surface temperature increasing to $200^{\circ} \mathrm{C}$. The value of heat flux also proves that the heat transfer rate of sample A6 is higher than the others. Thus, it takes short time for the gas generation from the device.

The real experiment is carried out to exam reliability of the calculation results. The power applied in the real test is fixed as $9.6 \mathrm{~W}$. This power makes temperature of $\mathrm{MCH}$ disk arise from 20 to $300^{\circ} \mathrm{C}$ in $1 \mathrm{~s}$. The results of the real test are presented in Fig. 9. The time needed for gas generation from the smoke atomizer 1 to 4 is $1.7,3.0,4.5$ and $6.6 \mathrm{~s}$ respectively. The results evidentially show that 
different porous ceramics have huge difference on the efficiency of gas generation even the smoke atomizer is small. The results of theoretical calculation are in fairly good agreement with the experimental result.

\section{Conclusions}

A high heat conductivity of porous ceramic was prepared to meet the requirement of smoke atomizer in "ecigarette". $\mathrm{SiC}$ and $\mathrm{Al}(\mathrm{OH})_{3}$ were the main raw materials. The application of both starch and graphite as pore forming agent is requisite to obtain the best comprehensive physical properties for smoke atomizer. The oil absorption of the best sample was $41.6 \%$ and the bending strength was $12.94 \mathrm{MPa}$. Mullite phase was found in the sample after fired at $1325^{\circ} \mathrm{C}$ according to SEM analysis. The porous ceramic was combined with $\mathrm{MCH}$ disk as a smoke atomizer. Both computational simulation and experimental research were used to exam the rate of gas generation. The application of porous ceramic prepared in this study on the smoke atomizer was with the highest efficiency of gas generation. The calculated results indicated the gas generated in $1.44 \mathrm{~s}$ and the real experiment show that the gas generated in $1.7 \mathrm{~s}$. The calculated results were advisable.

Acknowledgement The financial support on the Project 51502230 from National Natural Science Foundation of China is gratefully acknowledged. Financial support from China Tobacco Hubei Industrial LLC is also acknowledged here.

\section{References}

1) J. Foulds, S. Veldheer, J. Yingst and S. Hrabovsky, Nicotine Tob. Res., 17, 186-192 (2015).

2) T. Kirby, Lancet Resp. Med., 3, 750-751 (2015).

3) A. K. Frost, B. K. Zedler, G. Q. Line and H. J. Roethig, Regul. Toxicol. Pharm., 52, 118-121 (2008).

4) C. Huang, C.N. Patent 202999303 (2013).

5) P. F. Ou, S. Wang, H. Zhong and S. T. Wu, Ceram. Int., 38, 11-13 (2010).

6) S. Zhu, S. Ding, H. Xi, Q. Li and R. Wang, Ceram. Int.,
33, 115-118 (2007).

7) W. Wang, G. Hou, B. Wang and S. Deng, Mater. Chem. Phys., 147, 198-203 (2014).

8) W. Krenkel, B. Heidenreich and R. Renz, Adv. Eng. Mater., 4, 427-436 (2002).

9) J. H. Eom, Y. W. Kim, I. H. Song and H. D. Kim, Mater. Sci. Eng., R, 464, 129-134 (2007).

10) T. Mizuno and H. Kimata, U.S. Patent 6013898 (2000).

11) X. Guo, Ch. Ceram. Ind., 20, 9-11 (2013).

12) S. Ding, Y. P. Zeng and D. Jiang, Mater. Charact., 59, 140-143 (2008).

13) F. Tang, H. Fudouzi, T. Uchikoshi and Y. Sakka, J. Eur. Ceram. Soc., 24, 341-344 (2004).

14) A. Dey, N. Kayal, O. Chakrabarti, R. F. Caldato and V. G. Guerra, Int. J. Appl. Ceram. Tec., 11, 804-816 (2015).

15) Z. S. Jing, X. Y. Deng and J. B. Li, Ch. Ceram., 55, 14 18 (2013)

16) Z. S. Gu, Inorg. Chem., 23, 20-23 (1984).

17) B. Yang, W. Wang, L. Xu, G. C. Xu and F. L. Yang, J. Adv. Ceram., 30, 3-5 (2009).

18) Y. N. Jin, X. Y. Deng and J. B. Li, Ceram. Int., 41, 1418 (2013).

19) S. Q. Ding, Y. P. Zeng and D. L. Jiang, J. Inorg. Mater., 21, 1397-1403 (2006).

20) K. Wang and M. D. Sacks, J. Am. Ceram. Soc., 79, 1216 (2010).

21) W. L. Hong, W. Wang and Y. J. Guo, Adv. Mech. Eng., 37, 47-50 (2013).

22) V. D. Eisenhüttenleute, Slag atlas, second ed., Düsseldorf, Germany (1995) pp. 47, 154-155.

23) R. J. Angel and C. T. Prewitt, Am. Mineral., 71, 14761482 (1986).

24) M. Fukushima, H. Hyuga, C. Matsunaga and Y. I. Yoshizawa, J. Am. Ceram. Soc., 101, 15539-15582 (2018).

25) P. Liu, Q. Cai, C. Bai, X. Deng and L. J. Bao, Int. Mater. Rev., 29, 60-63 (2015).

26) D. R. Groft and D. G. Lilley, Appl. Sci.-Basel, 49, $922-$ 923 (1977).

27) L. F. Qian and R. C. Batra, Comput. Mech., 35, 214226 (2005). 